\title{
It's Everyone's Business: Capturing the Conversation
}

\author{
Darcy Burbage, MSN, RN, AOCN; Roshni Guerry, MD, FACP; Kristen Isaac, MPH \\ Christiana Care Health System, Newark, DE
}

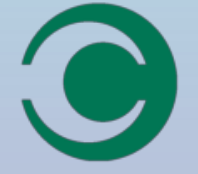

\section{CHRISTIANA CARE HEALTH SYSTEM}

Results of research studies show that clinicians typically avoid discussing goals of care $(\mathrm{GoC})$ and prognoses with patients. However, in order for patients facing serious illness to receive the care they want that is consistent with their values and wishes, health care providers must be skilled at challenging conversations. Currently, the GoC documentation is variable between generalist providers leaving the Palliative Care clinicians unclear as to if the discussions took place or what the patient and family members understood regarding their family member's quality of life goals. Because of this, a standardized GoC form was implemented in the EHR to help facilitate communication between clinicians that would be accessible for subsequent admissions and sudden changes in the patient's condition. The current standard of care is for clinicians to review $\mathrm{GoC}$ with patients upon admission and to document them in the GoC section of the EHR utilizing specific criteria. After an education session to all clinicians regarding the essential information to be included, GoC discussions were reviewed for all palliative care consults and rated as good, intermediate, or poor. Monthly standardized e-mail messages were sent to providers acknowledging good documentation as well as to offer assistance to improve discussion and documentation. Good GoC discussions increased by over $25 \%$ and patients with no GoC discussion decreased by over $20 \%$ during the initial study intervention.

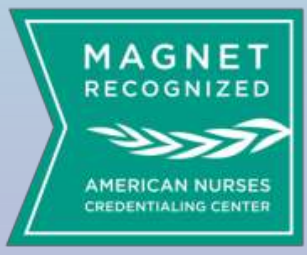

Communication improved between clinicians and the supportive and palliative team prior to consult which led to an increase in appropriate consults as well as an increase in primary palliative care provided by the referring clinicians. Our next steps are to implement an internal audit process for employed clinicians to improve $\mathrm{GoC}$ discussions and documentation in primary care practices, track how many GoC notes are translated to advance directives/POLST, conduct a survey to assess barriers to crucial conversations, increase Vital Talk course participation and CAPC communication module completion, and to increase engagement of nursing colleagues in the review of $\mathrm{GoC}$ notes on interdisciplinary team rounds.

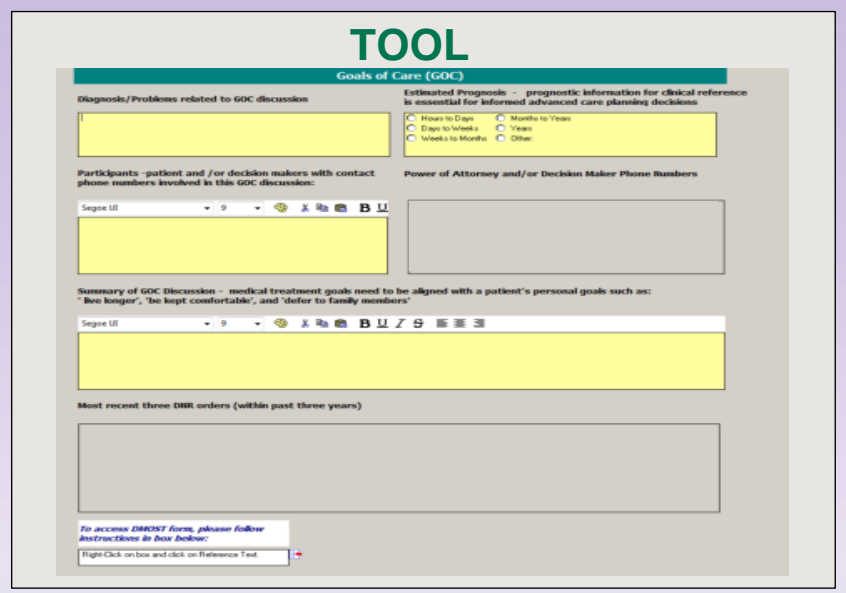

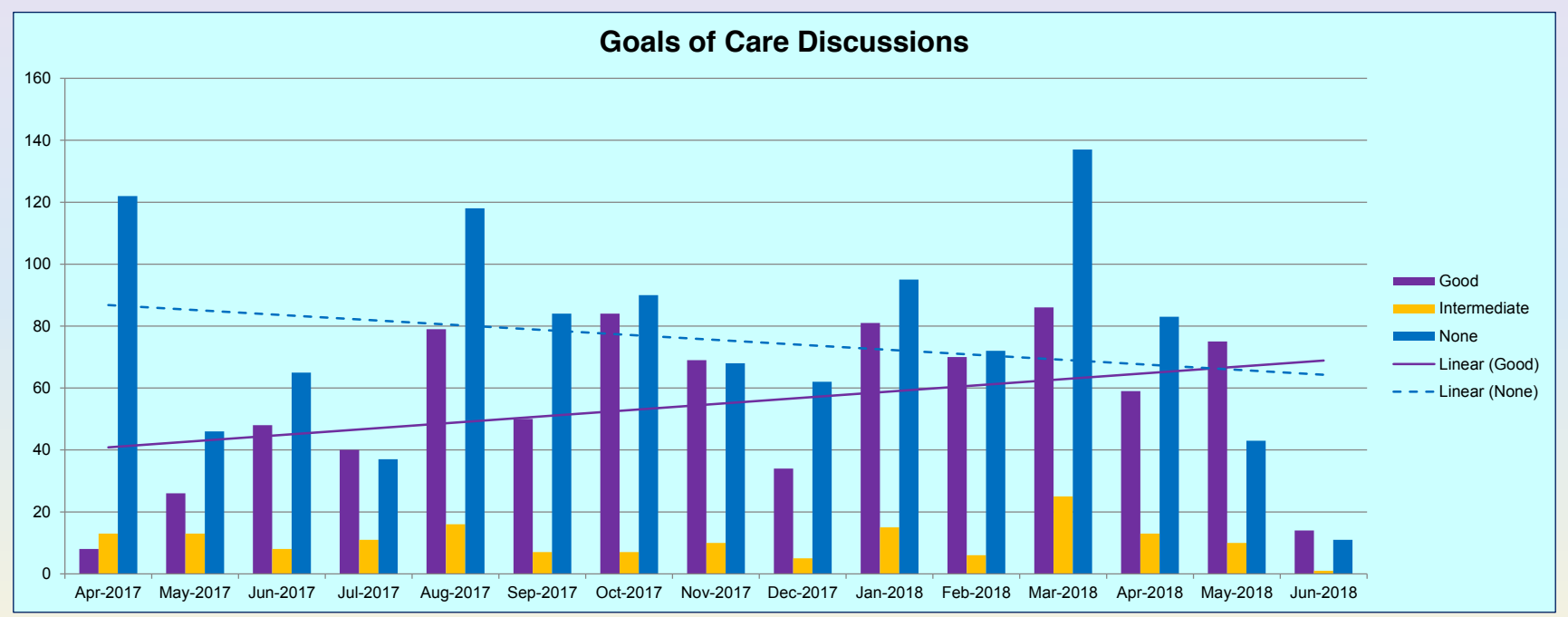

Bernacki, R. \& Block, S. (2014).

Bernacki, R. et al. (2015).

๑ 2019 Christiana Care Health Services, Inc., All rights reserved

Kamal, A. et al. (2015). 